\title{
Inspiraplex: The Respiratory Health Network
}

\author{
PETER T MACKLEM MD \\ Inspiraplex, Respiratory Health Network of Centres of Excellence, Montreal, Quebec
}

$\mathrm{C}$

ANADA IS NOT USUALLY THOUGHT OF AS A REVOLUTIONary country. Yet Canada has undergone two social revolutions that have dramatically improved the quality of life in this country and are continuing to do so. The first was adoption of universal medicare, which is unique in Canada because, in contrast to all other countries, there is no parallel private system. Wealthy Canadians who wish to purchase health care not available to the poor must do so outside of the country. The three leading indices by which a health care system is judged - infant mortality, maternal mortality and longevity at birth - places Canada among the top three countries in the world, along with Norway and Sweden. Japan, which leads in low infant mortality and longevity at birth, does not appear because of a remarkably high maternal mortality rate. The United States is pulled down because of the appalling health care statistics among the poor and the disadvantaged of that country. The United Kingdom lags because of inadequate funding. The medicare revolution made us world leaders in health care.

The second revolution was the Charter of Rights and Freedoms, which enshrined individual rights ahead of collective rights for the first time anywhere. In discussing our charter, Antonio Lamer, Chief Justice of the Supreme Court, said that "... the only country in the world that really acknowledged individual rights, the first country in the world, was Canada in 1982. In 1982 we put an end to legal positivism. Now that's a revolution. It was a great event."

In spite of our successes in health care and legal reform, Canadian industry - and with it, our economy - is faltering badly. According to the Organization for Economic Cooperation and Development (OECD), annual growth in Canadian productivity between 1979 and 1990 was $0.0 \%$, last among the Group of Seven (G7) countries. In its 1992 survey of the Canadian economy, the OECD noted that "the competitiveness of the Canadian economy ... has deteriorated markedly during the past two decades". Thus, the time is ripe for a third Canadian revolution - one that revitalizes our economy. This is what the Network of Centres of Excellence program hopes to accomplish by systematically incorporating the community of Canadian university scientists into the country's economy. This has not been accomplished in other countries. Indeed, existing economic theory regards science as an uncontrolled and confounding variable situated externally to the economy. We are an embarrassment and a difficulty -- expensive too - because research grants are considered as expenditures (anathema to capitalists) not investments (their food supply).

The fact that Canada is attempting to incorporate university science and scientists into the economy may be largely serendipitous. Our economists have recognized for a long time that continued dependence on environmentally unfriendly natural resource exploitation is a dead end for Canada. The necessity of changing from our traditional economic system to one based on knowledge and technology has been long recognized as a priority. The perplexing question was how to accomplish this, given our pathetically weak industrial research and development infrastructure. In Canada, industry-funded research and development as a percentage of gross domestic product is last among G7 countries. When the federal government began to consider these issues seriously in the mid-1980s they had little choice but to approach the university community for the development of new technologies because that was where practically all of the country's research was being done. They probably did not realize that they were tapping into a previously untapped and remarkable economic resource. According to data published in the Economist (1), shown in Table 1, Canada's scientists rank first in the world in terms of number of publications per capita and second only to the United States in terms of total impact (ie, number of publications per capita multiplied by the num-

Correspondence and reprints: Dr PT Macklem, Montreal Chest Institute, 3650 rue St-Urbain, Montréal, Québec H2X 2P4. Telephone (514) 845-6740, Fax (514) 845-8013 
TABLE 1

Research impact (data for 1991)

\begin{tabular}{|c|c|c|c|}
\hline Country & $\begin{array}{l}\text { Papers published/ } \\
100,000 \text { population/year }\end{array}$ & $\begin{array}{c}\text { Number of citations/ } \\
\text { paper published }\end{array}$ & $\begin{array}{l}\text { Papers published } \times \text { number of } \\
\text { citations }\left(\times 10^{-4}\right)\end{array}$ \\
\hline United States & 97 & 152 & 1.47 \\
\hline Canada & 111 & 109 & 1.21 \\
\hline United Kingdom & 101 & 116 & 1.17 \\
\hline Germany & 73 & 109 & 0.80 \\
\hline France & 63 & 103 & 0.65 \\
\hline Japan & 40 & 101 & 0.40 \\
\hline Italy & 35 & 93 & 0.33 \\
\hline
\end{tabular}

Data reproduced with modifications from the Economist (1)

ber of citations per paper). We have a considerable competitive advantage over countries such as Japan, Germany, France and Italy. In contrast to our industry and our economy, by world standards our science is excellent.

In 1988 the federal government announced the Network of Centres of Excellence program and called for applications from the Canadian scientific community. From the 158 applications received, 15 networks were chosen in all branches of science. One of them was Inspiraplex, the Respiratory Health Network of Centres of Excellence. Our focus is on diseases leading to airways obstruction, and our approach to these diseases has been traditional: pathology and pathophysiology, diagnosis, treatment, prevention and rehabilitation. This resulted in breadth of scope in our research and diversity in the number of scientific disciplines working together. This is at once both a strength and a weakness: a weakness because it makes it seem that our research program is unfocused, and a strength because diversity, a source of richness in itself, gives us access to an unprecedented range of expertise and extraordinary opportunities for interdisciplinary research.

The networks in general are mandated to develop intellectual property through scientific research that can be transferred to Canadian industry to create wealth and jobs and improve Canadian industrial competitiveness. We are supposed to do this by networking among sectors, universities and disciplines to create a whole that is greater than the sum of its parts. To accomplish these objectives, links needed to be established with industry to develop a receptor capacity to take on the new products and technologies developed by network scientists.

Inspiraplex completed its original four-year period of funding on April 30, 1994. Much of 1993 was spent doing the spade work, preparing for, writing and defending our renewal application for an additional four-year funding period. Near the end of March 1994, it was announced that we were one of the 10 renewed networks. One network did not reapply and four networks were unsuccessful.

The extensive amount of work that went into the renewal process resulted in considerable expansion and restructuring. We have adopted a matrix system in which the diseases of interest represent the vertical structures within the network, while the research disciplines we have chosen to investigate these diseases represent the horizontal structures (Figure 1).
There are six disease-related themes: asthma, chronic obstructive pulmonary disease (COPD), cystic fibrosis, environmental lung disease, sleep disordered breathing and respiratory failure. There are also six research discipline themes: molecular and cell biology, physiology, therapeutics, epidemiology, biomedical engineering and imaging.

Each theme has its own principal investigator: Jim Martin of McGill University for the asthma theme; Jim Hogg of the University of British Columbia for COPD; Sid Katz of UBC for cystic fibrosis; Margot Becklake of McGill and Moira Yeung of UBC jointly for environmental respiratory disease; John Remmers of the University of Calgary for sleep disordered breathing; and Magdy Younes of the University of Manitoba for respiratory failure. For the horizontal themes, Manuel Buchwald of the Hospital for Sick Children, University of Toronto is principle investigator for the molecular and cell biology theme; Art Slutsky of the University of Toronto for respiratory physiology; Pierre Ernst of McGill University for epidemiology; Pierre Sirois of l'Université de Sherbrooke for therapeutics; Jason Bates of McGill University for biomedical engineering; and David Eidelman of McGill University for medical imaging. Jason Bates is Associate Scientific Director for Research and Development and Jim Hogg is Associate Scientific Director for Medical Sciences. Anne Vézina (BArch MBA) is the executive director and keeps us all in line.

Because we are mandated to develop intellectual property that we can transfer to industry for economic benefit, those that stand to profit from our successes are the pharmaceutical and medical device industries. In selected areas we work closely with industry, for example, in collaborative asthma research with Merck Frosst Canada Inc. Merck Frosst has provided us with much support, including a competitive post-doctoral fellowship, free videoconferencing facilities, public relations and biologicals such as monoclonal antibodies. Because of considerable interest in medical devices being developed by network scientists, Respironics, an American medical device company, is establishing a small Canadian subsidiary to work closely with investigators in Winnipeg and Montreal. They provide Magdy Younes with a research fellow and proportional assist ventilation prototypes free of charge for testing.

Examples of intellectual property we are commercializing 


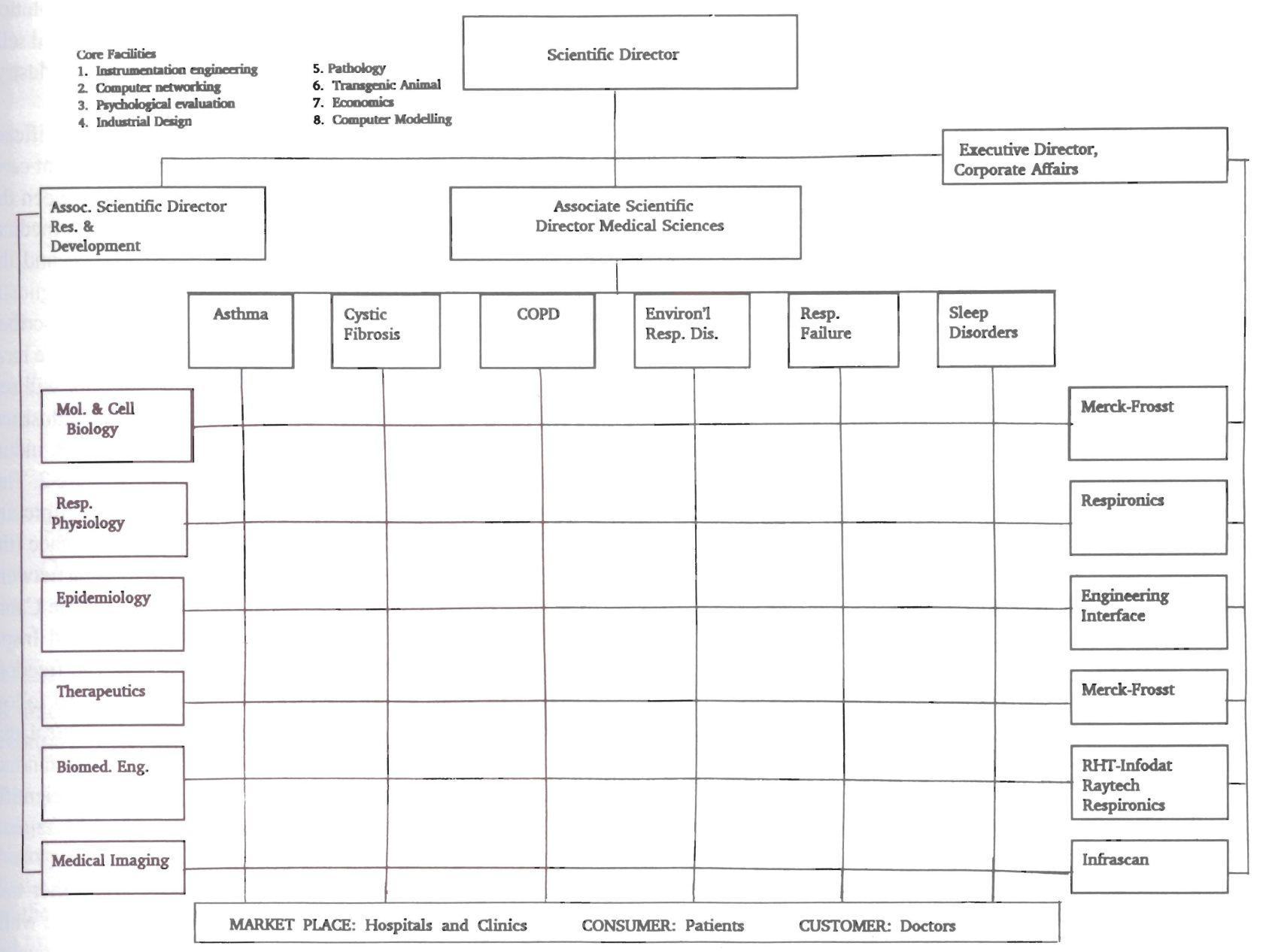

Figure 1) Organizational structure of Inspiraplex. Disease-related research themes are the vertical structures and link the patient population with respiratory disease. Research disciplines form the horizontal structures and link to industry because it is from these themes that new products and technologies arise. COPD Chronic obstructive pulmonary disease

include: proportional assist ventilation invented by Magdy Younes and developed for commercialization by network funds; a new office building ventilation system invented by an engineer associated with the network that may be useful in alleviating symptoms of the sick building syndrome; phosphatase inhibitors that increase the open probability of chloride channels in cystic fibrosis bronchial epithelium, discovered by John Hanrahan; and a diaphragmatic dynamometer in the process of commercialization by François Bellemare, based upon his work on diaphragmatic contractility estimated by bilateral, transcutaneous, supramaximal, phrenic nerve shocks.

The network is also mandated to improve the quality of life of Canadians, and here our stakeholders are the population of patients with respiratory disease. The disease-related themes link to the patient populations, while new products and technologies come out of the horizontal themes which link to industry. The commitment to both our patient population and our industrial partners is reflected in our mission statement: "Inspiraplex is a Canadian network of scientists whose mission is to conduct research to find innovative solutions to respiratory health problems thereby improving the quality of life of Canadians; to create technology that can be transferred into the market place to improve Canada's industrial competitiveness and thereby be of economic benefit to Canada; to train scientists to accomplish these objectives."

Those who have read Complexity: the Emerging Science at the Edge of Order and Chaos (2) will realize that systems that are greater than the sum of their parts are self-organizing, contain positive feedback loops and are never in equilibrium. Perturbations occurring in one element of the system lead to interactions with neighbouring elements and occasionally with elements at a distance. Interactions that are too extensive lead to chaotic, disordered behaviour. Interactions that are too few and too weak lead to inflexibility and fail to adapt to new challenges. Complex systems are neither chaotic nor in a steady state but do adapt and evolve in meaningful but generally unpredictable ways. We believe that the matrix structure with its interconnected elements is more likely to develop into a system in which the whole is greater than the sum of its parts than any top-down structure that we can 


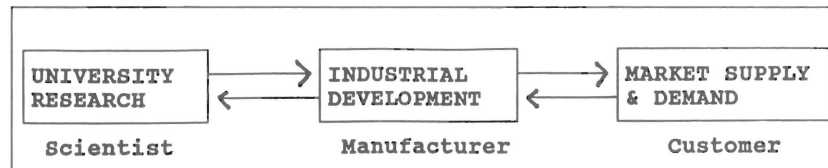

PHYSICIAN - SCIENTIST DOCTOR - CUSTOMER

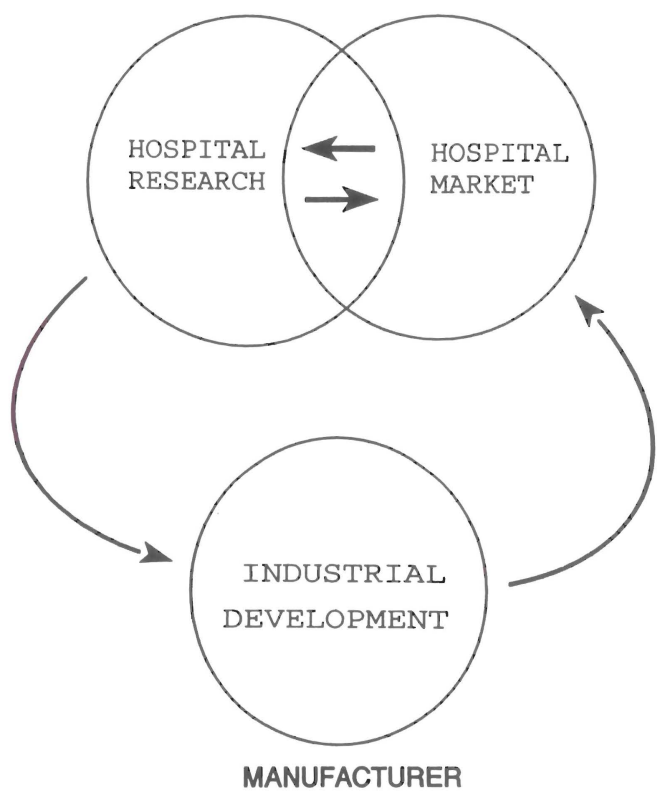

Figure 2) (Top) Model showing the interrelationships among the network, industry and the marketplace for a typical engineering network. (Bottom) Model showing the interrelationships among the network, industry and the marketplace for a biomedical network

imagine. Our structure is therefore specifically designed to foster the creativity that results in unpredictable but organized development at the edge of order and chaos.

Inspiraplex now extends from Halifax to Vancouver, linking investigators from Dalhousie University, Université Laval, Université de Sherbrooke, McGill University, Université de Montréal, Queen's University, University of Toronto, Hospital for Sick Children's Research Institute, McMaster University, University of Manitoba, University of Saskatchewan, University of Calgary, University of Alberta and University of British Columbia.

Biomedical networks such as Inspiraplex are different from engineering networks. Industries that link with engineering networks are supposed to understand the needs of their customers, and they understand the laws of supply and demand in the market place. They define the problems that university scientists can help to solve. These relationships are shown in the top of Figure 2. Industry, in responding to customer needs, tells the network what it wants; the network solves the problem by research and transfers the solution back to industry, which then manufactures, markets and sells to the customer. The network's research program is industrydriven.

The model for biomedical networks, in which a significant number of scientists is also practising hands-on patient care, is not the same. Here there is a major overlap between the customer and the researcher. For new drugs and medical devices, hospitals and clinics are the marketplace and the physician is the customer. It is doctors who order diagnostic tests and treatments; we determine what drugs are prescribed and ultimately what medical devices are purchased. We have a deeper understanding of what is needed and what will sell than either the pharmaceutical or medical device industries. This alters the relationship among network scientists, industry and the market, as shown in the bottom of Figure 2. This shows a two-way interchange between network clinicianscientists and practising physicians in the market place (the hospital) with a single unidirectional arrow from the network to industry to the customer. This is important for the Canadian respiratory research community in general and Inspiraplex in particular because it maintains academic freedom and scientific curiosity, allowing the investigator to follow his or her own star and minimizing industrial control that might inhibit creativity. I am not convinced that outstanding creativity and originality, essential ingredients in scientific excellence, are compatible with an industrially driven network.

Clearly a challenge that Inspiraplex and the other networks face is to maintain creativity and independence while delivering tangible economic benefit and improving quality of life. How to resolve these potentially contradictory demands should be vigorously debated over the next four years. The revolutionary attempt to incorporate the outstanding and hitherto untapped economic resource of the Canadian university scientists into the threatened Canadian economy to create wealth and jobs demands such a debate. The process must not be allowed to weaken Canadian science but must work to convert research grants from expenditures to investments. Economic dividends from investments in science would solve the problem of research funding. The network experiment must succeed because the potential benefits both to the economy and to science are large. Inspiraplex and the Canadian respiratory research community are proud that respiratory health has been selected as one of the scientific strengths on which to restructure our economy to achieve the third Canadian revolution.

\section{REFERENCES}

1. Economic and financial indicators The Economist 1992;

Dec 5-11:111.

2. Waldrop MM. Complexity: The Emerging Science at the Edge of Order and Chaos. New York: Simon \& Schuster, 1992. 


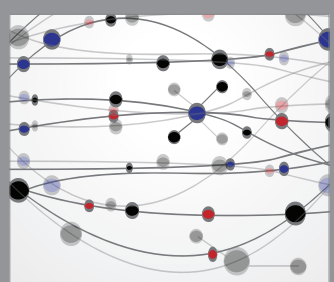

The Scientific World Journal
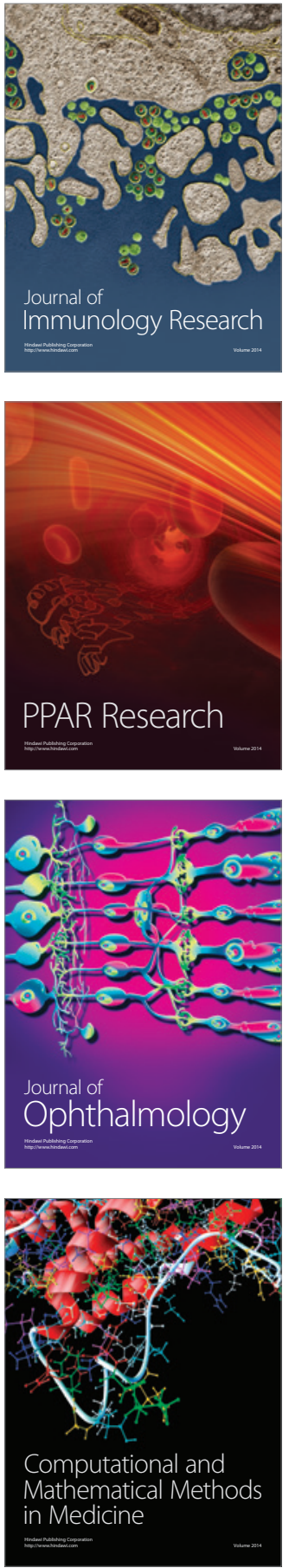

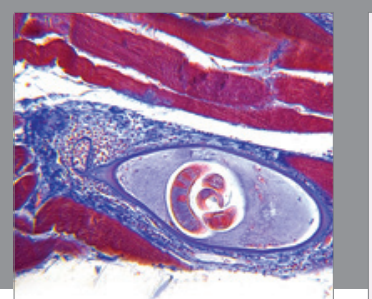

Gastroenterology Research and Practice

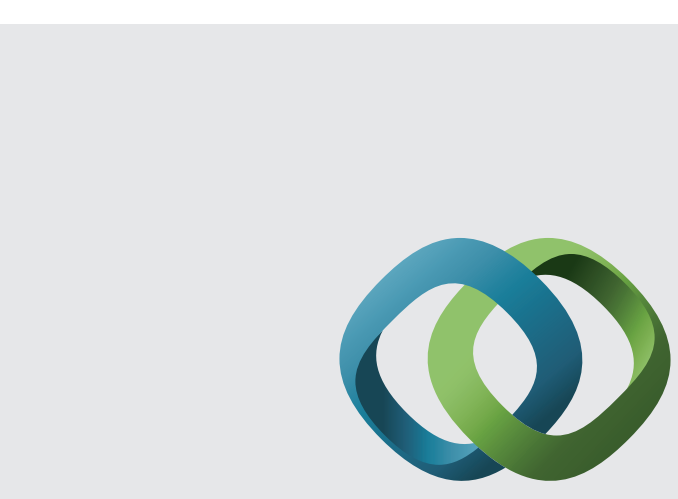

\section{Hindawi}

Submit your manuscripts at

http://www.hindawi.com
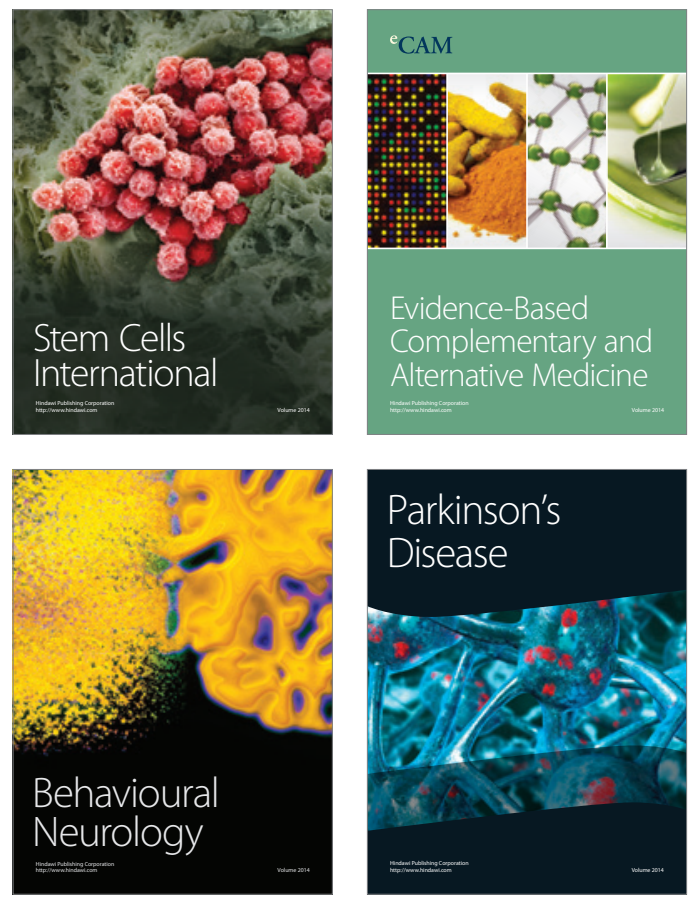
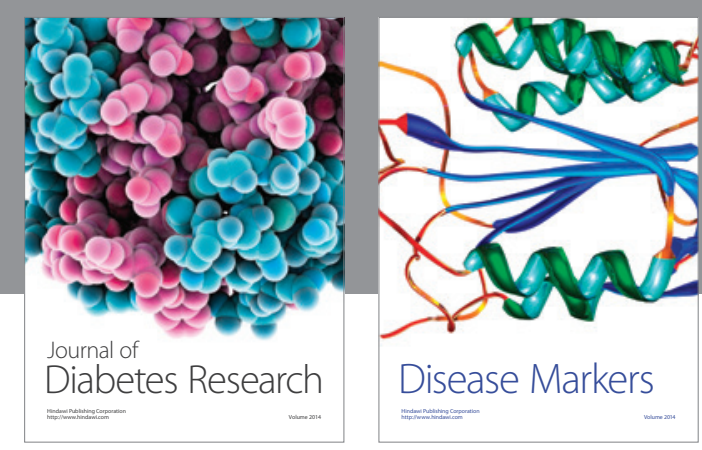

Disease Markers
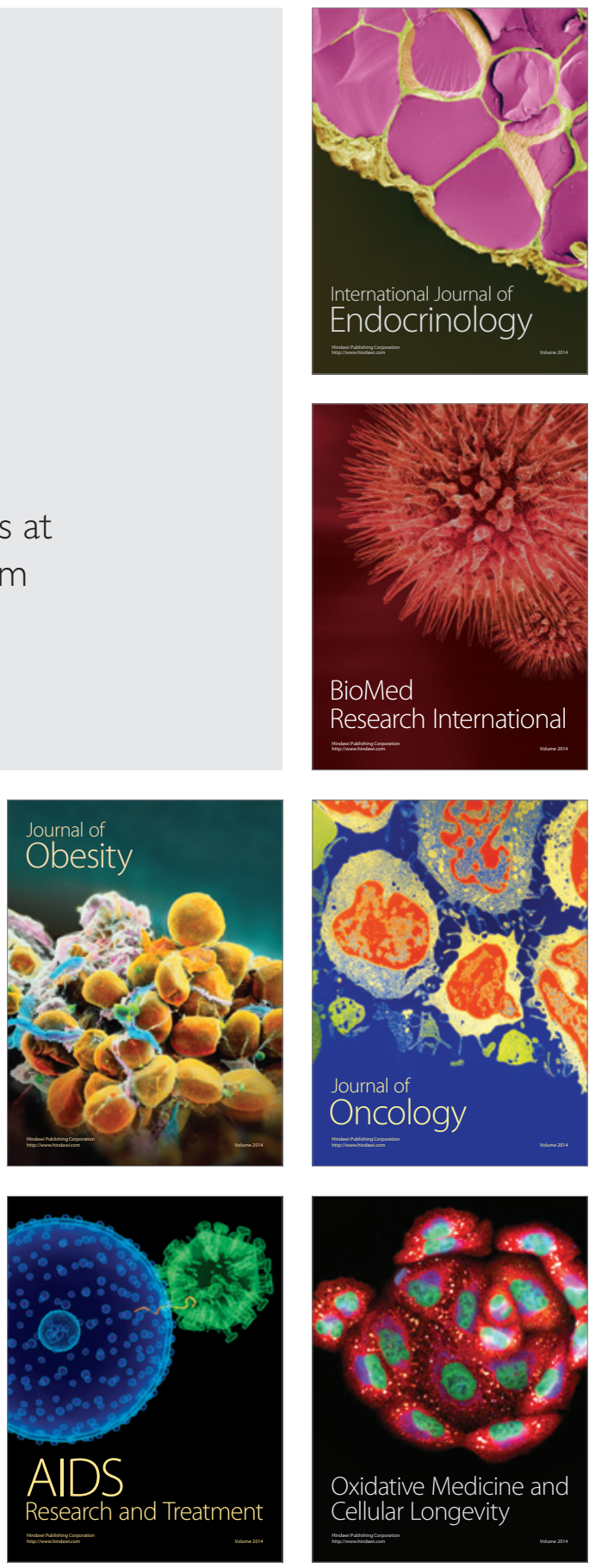